OLDONI, Fabiano. A constitucionalidade da fixação da fiança em salário mínimo no processo crime. Revista Eletrônica Direito e Política, Programa de Pós-Graduação Stricto Sensu em Ciência Jurídica da UNIVALI, Itajaí, v.10, n.2, $1^{0}$ quadrimestre de 2015. Disponível em: www.univali.br/direitoepolitica - ISSN 1980-7791.

\title{
A CONSTITUCIONALIDADE DA FIXAÇÃO DA FIANÇA EM SALÁRIO MÍNIMO NO PROCESSO CRIME
}

\author{
THE CONSTITUTIONALITY OF THE BAIL FIXING IN MINIMUM WAGE IN \\ THE PROCESS CRIME
}

Fabiano Oldoni $^{1}$

\begin{abstract}
SUMÁRIO: Introdução; 1. Função da fiança no processo crime; 2. O alcance da expressão "vedada sua vinculação para qualquer fim", contida no artigo 70, inciso IV, da CRFB/88; 3. A constitucionalidade da fixação da fiança em salários mínimos; Considerações Finais; Referências das Fontes Citadas.
\end{abstract}

RESUMO: O presente estudo objetiva analisar se a fixação da fiança em salários mínimos, previsto no artigo 325, incisos I e II do Código de Processo Penal, afronta o artigo 70, inciso IV, da Constituição Federal, que proíbe a vinculação do salário mínimo para qualquer finalidade. Justifica-se a presente pesquisa pela aparente inconstitucionalidade do citado artigo e pelo ineditismo do tema, eis que a matéria ainda não foi enfrentada pela doutrina e jurisprudência pátria de forma esclarecedora. De extrema importância investigar o sentido da proibição da vinculação ao salário mínimo contida na Constituição Federal, compreensão que se faz a partir dos julgados do Supremo Tribunal Federal, com aporte teórico na hermenêutica, buscando a interpretação mais adequada à Constituição².

Palavras-chave: Fiança; Salário Mínimo; Constitucionalidade; Processo Crime.

\footnotetext{
${ }^{1}$ Doutorando em Ciências Públicas na Escola de Direito da Universidade do Minho/-Portugal; Possui mestrado em Ciência Jurídica e Especialização em Direito Penal Empresarial pela Univali. É professor titular das disciplinas de Direito Processual Penal e Prática Jurídica Processual Penal pela Univali. Coordenador do Projeto de Execução Penal junto ao Sistema Penitenciário de Itajaí (convênio Univali/CNJ). Autor dos livros Para que $(\mathrm{m})$ serve o Direito Penal: uma análise criminológica da seletividade dos segmentos de controle social (2014 Lumen Juris); Aquisição da propriedade ilícita pela usucapião (2013 Paco Editorial) e Arrendamento Mercantil Financeiro: os efeitos do pagamento antecipado do Valor Residual e do Valor Residual Garantido (2006 Editora $\mathrm{BH}$ ), além de artigos publicados em revistas e periódicos. Advogado integrante de Silva \& Oldoni Advogados Associados. Blog em www.fabianooldoni.blogspot.com.br.

${ }^{2}$ A metodologia a ser utilizada no desenvolvimento da pesquisa compreende o método cartesiano quanto à coleta de dados e no relatório final o método indutivo com as técnicas do referente, da categoria, dos conceitos operacionais, da pesquisa bibliográfica e do fichamento.
} 
OLDONI, Fabiano. A constitucionalidade da fixação da fiança em salário mínimo no processo crime. Revista Eletrônica Direito e Política, Programa de Pós-Graduação Stricto Sensu em Ciência Jurídica da UNIVALI, Itajaí, v.10, n.2, $1^{\circ}$ quadrimestre de 2015. Disponível em: www.univali.br/direitoepolitica - ISSN 1980-7791.

ABSTRACT: The present study aims to analyze if bail fixing in minimum wages, foreseen in article 325, clauses I and II of the Penal Code Procedure, affront the article $7^{\text {th }}$, clause IV, of the Federal Constitution, which prohibits the linkage of the minimum wage to any purpose. Justifies, the present research, by the apparent unconstitutionality of the said article and the novelty of the theme, here is that the subject has not been dealt by the doctrine and the Brazilian jurisprudence in an enlightening way. Extremely important is to investigate the sense of the linkage of the minimum wage prohibition found in the Federal Constitution, the understanding which has been based by the judgments of the Federal Supreme Court, with theoretical support in hermeneutics, seeking the most appropriate interpretation to the Constitution.

Keywords: Bail; Minimum Wage; Constitutionality; Process Crime.

\section{INTRODUÇÃO}

O trabalho objetiva verificar se a fixação da fiança em salários mínimos, conforme preceitua o artigo 325, incisos I e II do Código de Processo Penal, afronta o artigo 70, inciso IV, da CRFB/88, que pró́be a vinculação do salário mínimo para qualquer finalidade ${ }^{3}$.

Justifica-se a presente pesquisa pela aparente inconstitucionalidade do artigo 325, incisos I e II do Código de Processo Penal e pelo ineditismo do tema, eis que a matéria ainda não foi enfrentada pela doutrina e jurisprudência pátria de forma esclarecedora.

Será pesquisado o sentido da expressão "vedada sua vinculação para qualquer fim", contida no artigo 70, inciso IV, da CRFB/88 e se referida vedação pode ser aplicada ao artigo 325, incisos I e II do CPP, com a nova redação dada pela Lei $12.403 / 2011$.

Esta compreensão é realizada a partir da análise dos julgados do Supremo Tribunal Federal, com aporte teórico na hermenêutica, buscando a interpretação mais adequada à Constituição.

\footnotetext{
${ }^{3}$ Apesar do Código de Processo Penal conter outras situações em que a vinculação ao salário mínimo acontece (artigos 219, 436 e 453), da mesma forma o Código Penal (artigo $45 \S 10$ e 49 § $\left.1^{\circ}\right)$, privilegiou-se o estudo da fiança, cuja conclusão poderá ser aplicada aos demais dispositivos legais, eis que apresentam similaridade no contexto jurídico penal e processual.
} 
OLDONI, Fabiano. A constitucionalidade da fixação da fiança em salário mínimo no processo crime. Revista Eletrônica Direito e Política, Programa de Pós-Graduação Stricto Sensu em Ciência Jurídica da UNIVALI, Itajaí, v.10, n.2, $1^{0}$ quadrimestre de 2015. Disponível em: www.univali.br/direitoepolitica - ISSN 1980-7791.

\section{FUNÇÃO DA FIANÇA NO PROCESSO CRIME}

A fiança, garantia constitucional aos crimes afiançáveis (artigo 50, inciso LXVI), é uma contracautela, uma garantia patrimonial, caução real, prestada pelo imputado e que se destina, inicialmente, ao pagamento das despesas processuais, multa e indenização, em caso de condenação, mas também, como fator inibidor da fuga ${ }^{4}$.

Para Lima5 ${ }^{5}$, com a alteração trazida pela Lei no 12.403/2011, a fiança deixou de ser apenas uma medida de contracautela (artigo 310, inciso III do CPP) e passou a funcionar também como medida cautelar autônoma, podendo ser determinada para assegurar o comparecimento a atos do processo, evitar a obstrução do seu andamento ou em caso de resistência injustificada à ordem judicial (artigo 319, inciso VIII do CPP).

Prevista no artigo 319, inciso VIII e $\S 40$, no artigo 322 e seguintes do Código de Processo Penal, o instituto da fiança tem no artigo 325, incisos I e II, os limites de seu arbitramento.

Segundo este artigo $^{6}$, a fiança poderá ser arbitrada entre 01 (um) a 100 (cem) salários mínimos, quando se tratar de infração cuja pena privativa de liberdade, no grau máximo, não for superior a 4 (quatro) anos e de 10 (dez) a 200 (duzentos) salários mínimos, quando o máximo da pena privativa de liberdade cominada for superior a 4 (quatro) anos ${ }^{7}$.

\footnotetext{
${ }^{4}$ LOPES JR, Aury. Direito Processual Penal. 10 ed., São Paulo: Saraiva, 2013, p. 901.

5 LIMA, Renato Brasileiro de. Manual de Processo Penal. Volume I, 2 ed., Niterói: Impetus, 2012, p. 1.484.

${ }^{6} \mathrm{O}$ artigo 325, alterado pela Lei no $12.403 / 11$, tinha a seguinte redação:

"Art. 325. O valor da fiança será fixado pela autoridade que a conceder nos seguintes limites:
}

a) de 1 (um) a 5 (cinco) salários mínimos de referência, quando se tratar de infração punida, no grau máximo, com pena privativa da liberdade, até 2 (dois) anos;

b) de 5 (cinco) a 20 (vinte) salários mínimos de referência, quando se tratar de infração punida com pena privativa da liberdade, no grau máximo, até 4 (quatro) anos;

c) de 20 (vinte) a 100 (cem) salários mínimos de referência, quando o máximo da pena cominada for superior a 4 (quatro) anos" (destacado).

7 Antes da alteração trazida pela Lei 12.403/11, o artigo 325 do CPP fazia menção ao salário mínimo de referência, o qual foi extinto com a Lei no 7.789/1989 (artigo 50), vigorando somente o 
OLDONI, Fabiano. A constitucionalidade da fixação da fiança em salário mínimo no processo crime. Revista Eletrônica Direito e Política, Programa de Pós-Graduação Stricto Sensu em Ciência Jurídica da UNIVALI, Itajaí, v.10, n.2, $1^{\circ}$ quadrimestre de 2015. Disponível em: www.univali.br/direitoepolitica - ISSN 1980-7791.

Contudo, o artigo 325, $\S 10$, do Código de Processo Penal, permite o aumento da fiança em até 1.000 (mil) vezes ou a redução em até o máximo de $2 / 3$ (dois terços).

Já o artigo 340 do Código de Processo Penal autoriza o juiz a exigir o reforço da fiança, caso tenha sido fixada em valor insuficiente, houver depreciação ou perecimento dos bens caucionados ou for inovada a classificação do delito para um crime mais grave, nos termos dos artigos 383 ou 384 do CPP. Em qualquer hipótese o reforço deve observar os limites fixados no artigo 325 do código.

Os critérios para a fixação do valor da fiança estão presentes no artigo 326 do Código de Processo Penal, e balizarão a autoridade no momento do arbitramento a natureza da infração, as condições pessoais de fortuna do preso, a vida pregressa, as circunstâncias indicativas de sua periculosidade e a importância provável das custas do processo até final julgamento.

Portanto, a questão que surge é se a fixação da fiança em salários mínimos afronta o artigo 70, inciso IV, da Constituição Federal.

Necessário se faz investigar qual o sentido da expressão "vedada sua vinculação para qualquer fim", contida na parte final do referido inciso, pois é a partir desta compreensão que se poderá, com mais segurança, firmar posição pela constitucionalidade ou não do artigo 325, incisos I e II do Código de Processo Penal.

\section{O ALCANCE dA expressão "VEdAda suA Vinculação para QUALQUER FIM", CONTIDA NO ARTIGO 70, INCISO IV, DA CRFB/88}

O artigo 70 inciso IV, da CRFB/88, apresenta a seguinte redação:

salário mínimo. Em seguida a Medida Provisória no 75/1989 descongelou o valor da fiança, e os valores expressos em quantidades de salário mínimo de referência (SMR), na legislação em vigor, ou a ele vinculados, passaram a ser calculados em função do BTN, à razão de 40 BTN para cada SMR. Em 1991 o BTN foi extinto. Com seu fim a autoridade deveria considerar o valor do último BTN (126,8621), e sobre esse valor aplicar a correção pela TR (LIMA, Renato Brasileiro de. Manual de Processo Penal. Volume I, 2 ed., Niterói: Impetus, 2012, p. 1.490). 
OLDONI, Fabiano. A constitucionalidade da fixação da fiança em salário mínimo no processo crime. Revista Eletrônica Direito e Política, Programa de Pós-Graduação Stricto Sensu em Ciência Jurídica da UNIVALI, Itajaí, v.10, n.2, $1^{\circ}$ quadrimestre de 2015. Disponível em: www.univali.br/direitoepolitica - ISSN 1980-7791.

Art. 70 São direitos dos trabalhadores urbanos e rurais, além de outros que visem à melhoria de sua condição social:

$(\ldots)$;

IV - salário mínimo, fixado em lei, nacionalmente unificado, capaz de atender a suas necessidades vitais básicas e às de sua família com moradia, alimentação, educação, saúde, lazer, vestuário, higiene, transporte e previdência social, com reajustes periódicos que lhe preservem o poder aquisitivo, sendo vedada sua vinculação para qualquer fim; (destacado).

Se por um lado o legislador assegurou quais as garantias básicas o salário mínimo deve garantir aos cidadãos, por outro, na parte final do inciso, proibiu expressamente a vinculação do salário mínimo para qualquer fim.

A questão é compreender qual o sentido e extensão desta proibição.

Para isso, procurou-se identificar a interpretação realizada pela Suprema Corte brasileira, nos vários julgamentos onde enfrentou o tema ${ }^{8}$.

Na ADI 14251-PE 9 , o Relator Ministro Marco Aurélio apresentou o entendimento de que o objetivo da proibição contida no artigo 70, inciso IV, da Constituição Federal é evitar que interesses outros, diversos da satisfação do piso constitucional, pudessem ter alguma influência relativamente ao quantitativo por ele representado, abrindo-se margem, assim, para a inobservância maior, decorrente do congelamento do salário mínimo, concernente ao atendimento das necessidades mencionadas no preceito.

No mesmo julgamento o Ministro Maurício Corrêa assinalou que a proibição é expressa, não permitindo a divagação com referência à sua imposição. Para o Ministro, se há esta vinculação, ela produz efeitos imediatos, tanto mais que quando houver o aumento do salário-mínimo, evidentemente haverá reflexos com relação ao pagamento dos vencimentos, ao recolhimento destas alíquotas.

\footnotetext{
${ }^{8}$ Os julgados não estão em ordem cronológica.

${ }^{9}$ Julgada em 1997.
} 
OLDONI, Fabiano. A constitucionalidade da fixação da fiança em salário mínimo no processo crime. Revista Eletrônica Direito e Política, Programa de Pós-Graduação Stricto Sensu em Ciência Jurídica da UNIVALI, Itajaí, v.10, n.2, $1^{\circ}$ quadrimestre de 2015. Disponível em: www.univali.br/direitoepolitica - ISSN 1980-7791.

O Ministro Sepúlveda Pertence, em seu voto na ADI, entendeu que a proibição da vinculação ao salário mínimo se dava para qualquer efeito, a partir da preocupação de não admitir a utilização do salário mínimo como indexador. Sustentou que a "inspiração dessa vedação constitucional vai mais longe" objetivando "evitar mecanismos de pressão de outros interesses, que sofreriam o reflexo do aumento o reflexo do aumento do salário mínimo, contra esse aumento em si mesmo".

Também para o Ministro Moreira Alves a proibição do artigo "se aplica quando houver qualquer empecilho ao aumento do salário por causa dessa vinculação".

Moreira Alves já havia se posicionado no RE 217.700-GO ${ }^{10}$, quando sustentou que a proibição "visa precipuamente a que ele (salário mínimo) não seja usado como fator de indexação, para que, com essa utilização, não se crie empecilho ao aumento dele em face da cadeia de aumentos que daí decorrerão, se admitida essa vinculação".

Novamente o Ministro Marco Aurélio, ao votar no Agravo Regimental em Agravo de Instrumento no $177959-M^{11}$, entendeu que a proibição alcança apenas a consideração do salário mínimo, como fator de indexação, atrelando-se parcelas devidas para que automaticamente façam-se corrigidas. E no RE 221.234-PR ${ }^{12}$, o Ministro observou que "o alcance do preceito não é senão evitar que o atrelamento do salário mínimo a situações diversas acabem por inibir o legislador na necessária reposição do poder aquisitivo da parcela".

Já no julgamento do Agravo de Instrumento 649.779-RJ ${ }^{13}$, a Ministra Carmen Lúcia entendeu que a proibição da vinculação ao salário mínimo se da inclusive para "efeito de fixação de multa administrativa", entendimento este mais amplo que os proferidos nos julgamentos acima. Aqui, segundo a Ministra, a vedação também se aplica nas situações que não pressionem o salário mínimo, numa

\footnotetext{
10 Julgado em 1994.

11 Julgado em 1997.

12 Julgado em 1998.

13 Julgado em 2007.
} 
OLDONI, Fabiano. A constitucionalidade da fixação da fiança em salário mínimo no processo crime. Revista Eletrônica Direito e Política, Programa de Pós-Graduação Stricto Sensu em Ciência Jurídica da UNIVALI, Itajaí, v.10, n.2, $1^{\circ}$ quadrimestre de 2015. Disponível em: www.univali.br/direitoepolitica - ISSN 1980-7791.

interpretação literal do dispositivo constitucional, que veda a vinculação para qualquer fim.

Neste sentido também já havia decidido o Ministro Moreira Alves, ao relatar o RE 237.965-SP ${ }^{14}$, quando ficou assentado o seguinte:

Dessa orientação não divergiu o acórdão recorrido - 0
Plenário desta Corte, ao julgar a ADIN 1425, firmou o
entendimento de que, ao estabelecer o artigo 70 , IV, da
Constituição que é vedada a vinculação ao salário-mínimo
para qualquer fim, "quis evitar que interesses estranhos aos
versados na norma constitucional venham a ter influência na
fixação do valor mínimo a ser observado". Ora, no caso, a
vinculação se dá para que o salário-mínimo atue como
fator de atualização da multa administrativa, que
variará com o aumento dele, o que se enquadra na
proibição do citado dispositivo constitucional
(destacado).

Carmen Lúcia, no voto proferido no RE 565.714-SP ${ }^{15}$, esclareceu, ainda, que um dos objetivos da proibição da vinculação é impedir que os aumentos do saláriomínimo gerem, indiretamente, um peso maior do que aquele diretamente relacionado com esses aumentos, circunstância que pressionaria para um reajuste menor do salário-minimo, o que significaria obstaculizar a implementação da política salarial prevista no referido artigo 70, inciso IV, da Constituição Federal.

Segundo a Ministra, este artigo é um dispositivo completo, pois além de determinar os objetivos a serem alcançados pelo salário-mínimo, cria o mecanismo obrigatório para atingi-los e evitar o retrocesso nas conquistas (reajustes periódicos que lhe preservem o poder aquisitivo), proibindo-se a prática de um dos obstáculos que impedem ou dificultem a suas concretizações, qual seja a vinculação para qualquer fim.

Contudo, nos idos de 1993, o Ministro Ilmar Galvão, ao relatar o RE 170.203-GO, havia dado uma interpretação mais flexível, ao autorizar a vinculação quando tenha por finalidade atender as mesmas garantias que a parte inicial do inciso IV

\footnotetext{
14 Julgado em 2000.

15 Julgado em 2008.
} 
OLDONI, Fabiano. A constitucionalidade da fixação da fiança em salário mínimo no processo crime. Revista Eletrônica Direito e Política, Programa de Pós-Graduação Stricto Sensu em Ciência Jurídica da UNIVALI, Itajaí, v.10, n.2, $1^{\circ}$ quadrimestre de 2015. Disponível em: www.univali.br/direitoepolitica - ISSN 1980-7791.

concede ao trabalhador e a sua família. Para ele, a proibição do salário mínimo como fator de indexação deve se dar para as "obrigações sem conteúdo salarial ou alimentar".

Já a ideia de se proibir a vinculação do salário mínimo como indexador para outros ganhos é bastante clara, tendo o Supremo editado a Súmula Vinculante no 4, nos seguintes termos:

Salvo nos casos previstos na Constituição, o salário mínimo não pode ser usado como indexador de base de cálculo de vantagem de servidor público ou de empregado, nem ser substituído por decisão judicial.

Esta súmula é restrita à proibição de indexar vantagens de servidor ou empregado ao salário mínimo, justamente porque esta prática pode impedir o seu aumento. Em outras palavras, o salário mínimo não pode gerar automaticamente aumentos em cascatas. Isso poderia gerar pressão para que o salário mínimo não sofresse reajustes. É justamente isso que não quis o legislador originário.

Assim é que ao não identificar qualquer possibilidade de pressionar ou impedir que o salário mínimo cumpra com seu papel (garantias básicas), é que o próprio Supremo, ao julgar a ADI $2.672^{16}$, reconheceu a constitucionalidade de lei do Estado do Espírito Santo que estabelecia o salário-mínimo como parâmetro para a definição de hipossuficiência econômica, para fins de inscrição gratuita em concurso público.

Neste julgamento, o voto divergente e vencedor do Ministro Carlos Brito foi no sentido de que "esse tipo de indexação ao salário mínimo não é proibido, por não ter relação com o processo inflacionário".

O Ministro Sepúlveda Pertence, ao acompanhar o voto dissidente, entendeu que não via "indexação ao salário mínimo". Segundo o Ministro, esta vinculação referida na lei (utilizar o salário mínimo como parâmetro de pobreza) não traz aqueles efeitos perversos de indexação, que evitem o aumento do salário mínimo

\footnotetext{
16 Julgado em 2006.
} 
OLDONI, Fabiano. A constitucionalidade da fixação da fiança em salário mínimo no processo crime. Revista Eletrônica Direito e Política, Programa de Pós-Graduação Stricto Sensu em Ciência Jurídica da UNIVALI, Itajaí, v.10, n.2, $1^{\circ}$ quadrimestre de 2015. Disponível em: www.univali.br/direitoepolitica - ISSN 1980-7791.

para evitar aumentar a isenção de taxa de concurso. Para ele, interpretar diferente é "levar longe demais a proibição da vinculação".

Também esclarecendo a extensão da proibição da vinculação é o voto do Ministro Moreira Alves, que atuou como Relator no RE 201.297-DF ${ }^{17}$ :

A vedação da vinculação do salário-mínimo contida na parte final do artigo 70, IV, da Constituição não tem sentido absoluto, mas deve ser entendida como vinculação de natureza econômica, para impedir que, com essa vinculação, se impossibilite ou se dificulte o cumprimento da norma na fixação do salário-mínimo compatível com as necessidades aludidas nesse dispositivo, bem como na concessão dos reajustes periódicos que the preservem o poder aquisitivo. A vinculação do valor da alçada ao salário-mínimo, para estabelecer quais são as causas de pequeno valor e que, portanto, devem ser decididas com a presteza de rito simplificado e com decisão de única instância ordinária, não se enquadra na finalidade a que visa a Constituição com a vedação por ela prevista, razão por que não é proibida constitucionalmente.

O Ministro, no ano de 2000, ao julgar o RE 237.965 acima referido, de certa forma alterou seu entendimento, pois neste julgamento acabou reconhecendo a inconstitucionalidade na vinculação ao salário mínimo de multa administrativa, numa visão menos flexível que a adotada no julgamento do RE 201.297-DF de 1996, a qual, pensamos, seja a mais apropriada.

Com isso tem-se que a vedação não é absoluta. A proibição somente se aplica quando o valor indexado ao salário mínimo possa, de alguma forma, influenciar no seu aumento futuro ou, de alguma forma, obstaculizar a implementação da política salarial prevista no artigo 70, inciso IV, da Constituição Federal

\footnotetext{
17 Julgado em 1996.
} 
OLDONI, Fabiano. A constitucionalidade da fixação da fiança em salário mínimo no processo crime. Revista Eletrônica Direito e Política, Programa de Pós-Graduação Stricto Sensu em Ciência Jurídica da UNIVALI, Itajaí, v.10, n.2, $1^{0}$ quadrimestre de 2015. Disponível em: www.univali.br/direitoepolitica - ISSN 1980-7791.

\section{A CONSTITUCIONALIDADE DA FIXAÇÃo DA FIANÇA EM SALÁRIOS MÍNIMOS}

Pelos julgados do Supremo Tribunal Federal, a proibição da vinculação do salário mínimo não é absoluta.

Mesmo que o dispositivo constitucional contenha a expressão para qualquer fim, o Supremo tem interpretado que a proibição da vinculação ao salário mínimo só afronta o artigo 70, inciso IV, da CRFB/88, se de alguma forma o valor vinculado possa impedir o aumento do salário mínimo.

Superada está a filosofia da consciência e a argumentação jurídica, onde a interpretação da lei se da a partir de opiniões pessoais do intérprete, de uma escolha do juiz, em que a subjetividade e o poder discricionário estão a toda evidência determinando o sentido do comando legal (solipsismo).

A quebra deste paradigma se dá com a hermenêutica filosófica (que procura dar sentido e não simplesmente interpretar) onde a compreensão antecipa a interpretação, com raiz em Gadamer.

Pela hermenêutica filosófica, não se escolhe uma decisão a ser tomada, mas toma-se a decisão mais adequada constitucionalmente. E esta decisão é aquela que está de acordo com a comunidade política.

Segundo Streck ${ }^{18}$ :

E esse ponto é absolutamente fundamental! Isso porque é o modo como se compreende esse sentido do direito projetado pela comunidade política (que é uma comunidade - virtuosa - de princípios) que condicionará a forma como a decisão jurídica será realizada de maneira que, somente a partir desse pressuposto, é que podemos falar em respostas corretas ou adequadas.

Portanto, mister que se observe qual era a intenção real do legislador originário (comunidade política) em proibir a vinculação de valores ao salário mínimo. Qual

18 STRECK, Lenio Luiz. O que é isto - decido conforme minha consciência? 4 ed., Porto Alegre: Livraria do Advogado, 2013, p. 108. 
OLDONI, Fabiano. A constitucionalidade da fixação da fiança em salário mínimo no processo crime. Revista Eletrônica Direito e Política, Programa de Pós-Graduação Stricto Sensu em Ciência Jurídica da UNIVALI, Itajaí, v.10, n.2, $1^{\circ}$ quadrimestre de 2015. Disponível em: www.univali.br/direitoepolitica - ISSN 1980-7791.

o sentido por traz desta proibição. Precisamos compreender para depois interpretar.

O sentido literal da expressão "para qualquer fim" pode indicar uma proibição absoluta e sem limites. Com Wittgenstein ${ }^{19}$, recusa-se esta interpretação simplista, já que "como não podemos de modo algum pensar em objetos espaciais fora do espaço, em objetos temporais fora do tempo, também não podemos pensar em nenhum objeto fora da possibilidade de sua ligação com outros".

Por tal razão é que a compreensão da expressão "para qualquer fim" não pode ser realizada de forma desvinculada ao contexto do artigo e do capítulo em que está inserido na Constituição (Capítulo II - Dos Direitos Sociais). A proibição não é apenas uma proibição. Ela quer dizer algo, representa um sentido, o qual deve ser buscado e compreendido.

E esta busca sempre deve ter por parâmetro a resposta mais adequada à Constituição, evitando, assim, o "julgo conforme minha consciência", que conduz à arbitrariedade e ao decisionismo, tão caro à filosofia da consciência e à argumentação jurídica. O juiz solipsista não tem mais lugar no Estado Democrático, onde toda a fundamentação deve ser buscada na Constituição, a qual expressa muito mais do que uma simples ordenação de poderes e fixação de direitos e garantias.

Explica Barreto ${ }^{20}$, que o Estado Democrático de Direito, do ponto de vista jurídico-constitucional, expressa, assim, uma ideia moral de organização do poder político, antes de ser uma ordenação dos poderes do Estado e de definição de direitos e garantias individuais e coletivas. É, portanto, consequência, e não fonte, de uma determinada concepção de homem e da sociedade, do homem considerado como ente moral, dotado de direitos anteriores à própria organização estatal.

${ }^{19}$ WITTGENSTEIN, Ludwig, Tractatus Logico-Philosophicus, Tradução de Luis Henrique Lopes dos Santos, São Paulo: Editora da Universidade de São Paulo, 2008, § 2.121.

20 BARRETO, Vicente de Paulo. Da interpretação à hermenêutica constitucional. In Margarida Lacombe (org.). 1988-1998: uma década de Constituição. Rio de Janeiro: Renovar, 1999, p. 391. 
OLDONI, Fabiano. A constitucionalidade da fixação da fiança em salário mínimo no processo crime. Revista Eletrônica Direito e Política, Programa de Pós-Graduação Stricto Sensu em Ciência Jurídica da UNIVALI, Itajaí, v.10, n.2, $1^{\circ}$ quadrimestre de 2015. Disponível em: www.univali.br/direitoepolitica - ISSN 1980-7791.

E a hermenêutica tem papel importante nesta nova leitura, já que para ela a aplicação da Constituição representa a concretização do conteúdo substancial e dirigente do texto, apostando realização dos direitos substantivos, que tem caráter cogente, de onde decorre uma maior valorização da jurisdição constitucional ${ }^{21}$.

Nas inúmeras vezes que o Supremo enfrentou o tema, parece ter ficado bastante claro qual o sentido extraído da proibição da vinculação ao salário mínimo. Também se pode compreender que esta proibição não é absoluta.

O sentido da proibição é evitar que o salário mínimo tenha retrocesso nas conquistas (reajustes periódicos que lhe preservem o poder aquisitivo) e evitar mecanismos de pressão de outros interesses, que sofreriam o reflexo do aumento do salário mínimo.

Não nos parece que a vinculação da fiança em salários mínimos possa ser considerado um obstáculo que impeça ou dificulte as concretizações do salário mínimo (Mina. Carmem Lúcia). Também não nos parece que esta vinculação possa ter relação com o processo inflacionário (Min. Carlos Brito) e tampouco possa criar empecilho ao aumento dele em face da cadeia de aumentos que daí decorrerão, se admitida essa vinculação (Min. Moreira Alves).

Por mais que o Supremo tenha, em dois julgados ${ }^{22}$ analisados, reconhecido a inconstitucionalidade de lei que vinculava multa administrativa ao salário mínimo, mesmo sem a potencialidade de existir os reflexos acima mencionados, o entendimento majoritário da Corte e mais adequado ao texto constitucional, é de reconhecer a proibição da vinculação ao salário mínimo somente quando a vinculação for de natureza econômica, justamente "para impedir que, com essa vinculação, se impossibilite ou se dificulte o cumprimento da norma na fixação do salário-mínimo compatível com as necessidades aludidas nesse dispositivo, bem

\footnotetext{
${ }^{21}$ STRECK, Lenio Luiz. Verdade e Consenso. 3 ed., Rio de Janeiro: Lumen Juris, 2009, p. 176.

${ }^{22}$ RE 237.965 e AI 649.779.
} 
OLDONI, Fabiano. A constitucionalidade da fixação da fiança em salário mínimo no processo crime. Revista Eletrônica Direito e Política, Programa de Pós-Graduação Stricto Sensu em Ciência Jurídica da UNIVALI, Itajaí, v.10, n.2, $1^{\circ}$ quadrimestre de 2015. Disponível em: www.univali.br/direitoepolitica - ISSN 1980-7791.

como na concessão dos reajustes periódicos que lhe preservem o poder aquisitivo" ${ }^{23}$.

Desta forma, pode-se concluir que a fixação da fiança em salários mínimos, contida no artigo 325, incisos I e II do CPP, não ofende o artigo 70, inciso IV, da CRFB/88, pois não impede e nem dificulta que o salário mínimo possa cumprir com os objetivos traçados nos mesmo dispositivo legal.

\section{CONSIDERAÇÕES FINAIS}

A proposta do trabalho foi analisar se o artigo 325, incisos I e II do Código de Processo Penal, com a alteração da Lei no 12.403/11, que fixa a fiança em salários mínimos, afronta o artigo 70, inciso IV, da Constituição Federal, que proíbe a vinculação do salário mínimo para qualquer fim.

Para tanto foi verificado, inicialmente, o conceito de fiança e sua função no processo crime. Na sequência abordou-se qual o sentido da proibição da vinculação ao salário mínimo, contida na norma constitucional.

Utilizou de alguns julgados do Supremo Tribunal Federal, onde em seus votos os ministros acabam por tecer considerações a respeito do sentido desta proibição, sendo algumas com maior extensão e flexibilidade, como é o caso da proibição da vinculação ao salário mínimo de multas administrativas.

Apesar destes entendimentos isolados, a ideia principal contida nos julgados é a de que a expressão "sendo vedada sua vinculação para qualquer fim" não pode ser interpretada de forma absoluta. A relativização ficou clara no julgamento da ADI 2.672, em que a Corte reconheceu a constitucionalidade de lei do Estado do Espírito Santo que estabelecia o salário-mínimo como parâmetro para a definição de hipossuficiência econômica, para fins de inscrição gratuita em concurso público.

\footnotetext{
23 Parte do voto do Min. Moreira Alves no RE 201.297-DF.
} 
OLDONI, Fabiano. A constitucionalidade da fixação da fiança em salário mínimo no processo crime. Revista Eletrônica Direito e Política, Programa de Pós-Graduação Stricto Sensu em Ciência Jurídica da UNIVALI, Itajaí, v.10, n.2, $1^{\circ}$ quadrimestre de 2015. Disponível em: www.univali.br/direitoepolitica - ISSN 1980-7791.

Outra decisão que evidencia a flexibilização da proibição foi a proferida no RE 201.297-DF, onde ficou assentado que a vedação da vinculação do saláriomínimo não tem sentido absoluto, mas deve ser entendida como vinculação de natureza econômica, para impedir que, com essa vinculação, se impossibilite ou se dificulte o cumprimento da norma na fixação do salário-mínimo compatível com as necessidades aludidas nesse dispositivo, bem como na concessão dos reajustes periódicos que Ihe preservem o poder aquisitivo.

O que ficou bastante claro nos julgamentos analisados, é que o Supremo Tribunal Federal entende que a proibição deve ser aplicada quando a vinculação ao salário mínimo possa ser considerado um obstáculo que impeça ou dificulte as concretizações do salário mínimo (Mina. Carmem Lúcia), ou que esta vinculação possa influenciar o processo inflacionário (Min. Carlos Brito) ou, ainda, possa criar empecilho ao aumento do salário mínimo, em face da cadeia de aumentos que daí decorrerão, se admitida essa vinculação (Min. Moreira Alves).

Ou ainda, conforme voto do Min. Marco Aurélio, a proibição tem por sentido evitar que interesses outros, diversos da satisfação do piso constitucional, possam ter alguma influência relativamente ao quantitativo por ele (salário mínimo) representado, abrindo-se margem, assim, para a inobservância maior, decorrente do congelamento do salário mínimo, concernente ao atendimento das necessidades mencionadas no preceito.

A pesquisa utilizou-se do aporte teórico da hermenêutica filosófica, onde a compreensão antecede a interpretação, compreensão esta que se da a partir do entendimento da comunidade política, no caso o poder constituinte originário, afastando-se, assim, o entendimento solipsista, bem como a argumentação jurídica e a filosofia da consciência.

Por fim, entende-se que o artigo 325, incisos I e II do Código de Processo Penal, com a alteração da Lei no 12.403/11, que fixa a fiança em salários mínimos, não afronta 0 artigo 70, inciso IV, da Constituição Federal, que proíbe a vinculação do salário mínimo para qualquer fim. 
OLDONI, Fabiano. A constitucionalidade da fixação da fiança em salário mínimo no processo crime. Revista Eletrônica Direito e Política, Programa de Pós-Graduação Stricto Sensu em Ciência Jurídica da UNIVALI, Itajaí, v.10, n.2, $1^{\circ}$ quadrimestre de 2015. Disponível em: www.univali.br/direitoepolitica - ISSN 1980-7791.

Este entendimento firmou-se a partir da compreensão de que o arbitramento da fiança em salários mínimos não impede e nem dificulta que o salário mínimo possa cumprir com os objetivos traçados no artigo 70, inciso IV, da Constituição Federal, justamente por não exercer nenhuma pressão sobre o mesmo que possa obstaculizar o seu aumento periódico.

\section{REFERÊNCIAS DAS FONTES CITADAS}

BARRETO, Vicente de Paulo. Da interpretação à hermenêutica constitucional. In Margarida Lacombe (org.). 1988-1998: uma década de Constituição. Rio de Janeiro: Renovar, 1999.

BRASIL. Supremo Tribunal Federal, ADI 14251-PE, Rel. Min. Marco Aurélio, j. em 01/10/1997.

BRASIL. Supremo Tribunal Federal, ADI 2.672, Rel. Min. Ellen Gracie, j. em $22 / 6 / 2006$.

BRASIL. Supremo Tribunal Federal, Agravo Regimental em Agravo de Instrumento no 177959-MG, Rel. Min. Marco Aurélio, j. em 04/3/1997.

BRASIL. Supremo Tribunal Federal, Agravo de Instrumento 649.779-RJ, Rel. Min. Carmen Lúcia, j. em 24/3/2009.

BRASIL. Supremo Tribunal Federal, Recurso Extraordinário 217.700-Go, Rel. Min. Moreira Alves, j. em 12/4/1994.

BRASIL. Supremo Tribunal Federal, Recurso Extraordinário 221.234-PR, Rel. Min. Marco Aurélio, j. em 02/10/1998.

BRASIL. Supremo Tribunal Federal, Recurso Extraordinário 237.965-SP, Rel. Min. Moreira Alves, j. em 10/02/2000.

BRASIL. Supremo Tribunal Federal, Recurso Extraordinário 565.714-SP, Rel. Min. Carmen Lúcia, j. em 30/4/2008. 
OLDONI, Fabiano. A constitucionalidade da fixação da fiança em salário mínimo no processo crime. Revista Eletrônica Direito e Política, Programa de Pós-Graduação Stricto Sensu em Ciência Jurídica da UNIVALI, Itajaí, v.10, n.2, $1^{\circ}$ quadrimestre de 2015. Disponível em: www.univali.br/direitoepolitica - ISSN 1980-7791.

BRASIL. Supremo Tribunal Federal, Recurso Extraordinário 201.297-DF, Rel. Min. Moreira Alves, j. em 01/10/1996.

BRASIL. Supremo Tribunal Federal, Recurso Extraordinário 170.203-Go , Rel. Min. Ilmar Galvão, j. em 30/11/1993.

LIMA, Renato Brasileiro de. Manual de Processo Penal. Volume I, 2 ed., Niterói: Impetus, 2012.

LOPES JR, Aury. Direito Processual Penal. 10 ed., São Paulo: Saraiva, 2013.

STRECK, Lenio Luiz. O que é isto - decido conforme minha consciência? 4 ed., Porto Alegre: Livraria do Advogado, 2013.

Verdade e Consenso. 3 ed., Rio de Janeiro: Lumen

Juris, 2009.

WITTGENSTEIN, Ludwig, Tractatus Logico-Philosophicus, Tradução de Luis Henrique Lopes dos Santos, São Paulo: Editora da Universidade de São Paulo, 2008.

Submetido em: Fevereiro/2015

Aprovado em: Março/2015 